\title{
Using an Equilibrium Model to Forecast Airline Behavior in response to Economic or Regulatory Changes
}

\author{
John Ferguson; Karla Hoffman; Lance Sherry; George Donohue; Abdul Qadar Kara \\ Center for Air Transportation Systems Research, George Mason University, Fairfax, VA \\ Rosa Oseguera-Lohr
}

NASA Langley Research Center, Aeronautics Systems Analysis Branch, Hampton, VA 23681

\begin{abstract}
Government and industry are exploring approaches, such as technology (e.g. SESAR/NextGen) and market-based methods, to address the pervasive delays in the air transportation system. Resistance to some of the proposed market-based strategies are based on uncertainties of the societal and economic outcomes; specifically, there is a concern that fewer markets might be served, that service within existing markets might be decreased, that airfares might rise significantly and that airline profitability will suffer.
\end{abstract}

This paper describes a comparison of the behavior of the air transportation system (e.g. markets served, airfares, delays, load factors, aircraft size) during the recent run-up in fuel prices at capacity-limited New York airports and non-slot controlled San Francisco and Philadelphia airports.

The results of the modeled airline behavior shows:

i. Airfares change in proportion to changes in fuel prices.

ii. Flights per day and markets served change in proportion to changes in airport capacity limits.

iii. Average aircraft size changes in proportion to changes in airfares, number of markets served, and number of flights per day.

iv. Airline profitability changes in proportion to flights per day, airfares, and average aircraft size.

The implications of these results are discussed in this paper.

Keywords: Economic analysis, performance metrics, longitudinal analysis, airport delays, market analysis, metroplex.

\section{INTRODUCTION}

The air transportation system is a significant driver of the U.S. economy providing safe, affordable, and rapid transportation [1]. During the past three decades airspace and airport capacity has not grown in step with demand for air transportation which is projected to grow at average annual growth of $+3.5 \%$ [2] . The failure to increase capacity at the same rate as the growth in demand will result in unreliable service and systemic delays [3][4]. Estimates made on the impact of delays and unreliable service on the economy range from $\$ 32$ $\mathrm{B} /$ year [5] to $\$ 41 \mathrm{~B} /$ year [6].

Government and industry have explored three approaches to address this capacity-demand growth imbalance:

1. Increasing the capacity of the airports and airspace to handle additional flights. The Airport Improvement Plan [7] is designed to relieve the bottlenecks at U.S. airports by adding runways, taxiways, gates, terminal buildings and service facilities to key nodes of the air transportation system.

The impact of these initiatives on the most capacitated airports is limited due to the lack of additional real-estate to accommodate needed infrastructure (e.g. additional runways). For these airports special use airspace (e.g. military use only) has been made available to increase the number of flights that can be handled during periods of peak demand. Plans are also underway to improve landing and takeoff technologies that will allow "all weather" operations.

2. Modernization of U.S. Air Traffic Control (ATC). A \$37B modernization program, known as NextGen [8], will improve productivity and the utilization of existing airspace. This will yield increases in the effective-capacity of the airspace 
and airports. Improvements in flow management, airborne re-routing, 4-D coordination of flights, and super-dense operations will increase the number of flights that can be handled during peak-periods. Estimates made for increasing effective capacity at the bottlenecks range from a total increase of $10 \%$ to $30 \%$. These increases are significantly lower than a compounded $4 \%$ annual growth rate in demand.

3. Increase Passenger Capacity per Flight. Regulators have considered incentives for airlines to increase the size of aircraft to transport more passengers per runway/airspace slots [9]. Under these incentives, the government or port authority would regulate the scheduled operations to match the number of runway slots and gates available. The slots would be allocated to ensure competition between airlines to maintain competitive airfares and service, as well as to provide economies of scale and network integrity for airline networks. Allocation schemes range from administrative (e.g. grandfathering, voluntary agreements between airlines and the FAA, or political allocations) to market-based mechanisms (e.g. congestion pricing, auctions). Care must be taken with these schemes to ensure the most efficient economic and sociopolitical use of the slots, and to ensure competition.

The idea of improved utilization of runway/airspace capacity through increased aircraft size gained some traction in 2007 and 2008. This resulted in new and adjusted capacity limits at the major New York and Newark airports. Specifically a Department of Transportation initiative coordinated capacity limits at the three New York airports (JFK - 81 per hour (1/18/2008), EWR - 81 per hour $(5 / 21 / 2008)$, LGA - decreased from $75 /$ hour +6 unscheduled to 71 /hour +3 unscheduled (1/15/2009). The slots at each of the airports were allocated by grandfathering. The concept of auctioning the slots to maximize the economic efficiency in the allocation and to ensure competitive airfares and service met strong criticism and was withdrawn.

The objections to the concept were based on concerns that the introduction of capacity limits and market-based allocation schemes would affect:

1. Geographic access to air transportation service (i.e. elimination of service at smaller markets)
2. Economic access to air transportation service (i.e. increased operational costs could lead to increased airfares, that might be too costly for certain segments of the population).

3. Airline finances in a negative manner (i.e. reduced profits due to additional costs of operation)

4. Air Transportation Efficiency as measured by the seats per runway/airspace slot (also known as aircraft size or aircraft gauge).

This paper describes the results of an analysis that examines how the airline industry in the aggregate may react to changes in operational costs and reductions in runway access.

This study examines airline responses to altering airport capacity limits, to varying operating cost conditions, and to varying passenger demand because of changes in economic conditions. In the model the impacts of operating costs are examined by varying fuel prices, and use data on passenger demand that reflect the distribution of prices (demand curves) paid by passengers to each market served during the summer of 2007.

Table 1 summarizes the Airport Schedule Optimization Model (ASOM) modeled airline behavior in response to changes in airport capacity and operational costs. The implications of this analysis are summarized below:

1. As capacity limits are imposed (i.e. -4 operations per hour), the ASOM aggregated airline reduces markets by $0.6 \%$, decreases scheduled flights per day to all markets by $1.5 \%$, increases average revenue per seat by $0.2 \%$, increases average aircraft size by $0.3 \%$, and reduces daily airline profits by $0.7 \%$.

2. As hedged fuel prices increase $\$ .45$ per gallon (e.g. equivalent to doubling landing fees from \$1000 to \$2000 per operation), the ASOM aggregated airline reduces markets by $0.9 \%$, decreases scheduled flights per day to all markets by $1.0 \%$, increases average airfare by $4.5 \%$, decreases average aircraft size by $1.3 \%$, and increases daily airline profits by $0.3 \%$. 


\begin{tabular}{|c|c|c|}
\hline $\begin{array}{c}\text { LGA, EWR, } \\
\text { JFK, SFO, } \\
\text { PHL }\end{array}$ & $\begin{array}{c}\text { Effect from reduction } \\
\text { of 4 ops per hour }\end{array}$ & $\begin{array}{c}\text { Effect from \$.45 } \\
\text { increase in Fuel Prices }\end{array}$ \\
\cline { 2 - 3 } 3QTR 07 Fuel Prices & MVFR airport capacity \\
\hline Markets & $-0.6 \%$ & $-0.9 \%$ \\
\hline $\begin{array}{c}\text { Daily } \\
\text { Flights }\end{array}$ & $-1.5 \%$ & $-1.0 \%$ \\
\hline Rev/Seat & $+0.2 \%$ & $+4.5 \%$ \\
\hline Gauge & $+0.3 \%$ & $-1.3 \%$ \\
\hline $\begin{array}{c}\text { Daily } \\
\text { Profits }\end{array}$ & $-0.7 \%$ & $+0.3 \%$ \\
\hline
\end{tabular}

Table 1. ASOM Modeled Airline behavior for 3QTR 07 in response to changes in capacity and operational costs.

This analysis finds that the Air Transportation System shows relatively minor changes in geographic access, economic access and airline profitability even when prices increase or when capacity is reduced somewhat.

This analysis shows in the presence of increased passenger demand and in the absence of significant airline competition the airline industry will increase aircraft size. However, this finding is not consistent with our observations from historical data where up-guaging has not taken place. The major reasons for this discrepancy is that the model does not consider: (1) the capital costs of purchasing new aircraft since there is a lack of available aircraft at the 90-120 seat size (2) the airline's preference toward frequency (in order to maintain market share and provide passengers with more time-specific options), and (3) labor cost structures for pilots that are significantly higher for larger aircraft than for regional jets.

This paper is organized as follows: a section to describe the study's methodology, a section to describe the study results, and a final section to summarize the conclusions from the study.

\section{METHOD OF ANALYSIS}

\section{A. Airport Schedule Optimization Model (ASOM)}

The ASOM is a multi-commodity model that optimizes the schedule of aircraft serving an airport while satisfying market demand. The ASOM, based on an earlier model [10] selects an optimal schedule for an airport by selecting profitable markets that can be serviced by the airport, and then allowing the profitable markets to compete for scheduled flights within the fixed capacity of the airport.

This analysis captures the impact of the implementation of capacity limits at the airports, as well as the effect of increased costs of operation (e.g.. hedged fuel prices). The increases in fuel costs can serve as a proxy for increased costs per flight that might occur if auctions or congestion pricing are imposed or if there are other shocks impacting airline costs. The model also incorporates demand elasticity curves based on historical data that provide information about how passenger demand is impacted by airfare changes.

The Airline Schedule Optimization Model (ASOM) is used in this study to examine airline and passenger responses to altering airport capacity limits, to varying operating cost conditions. The model also captures the responses of passengers to airline posted prices, economic conditions and availability of service. For any collection of changes, ASOM determines the equilibrium supply and demand prices.

The ASOM models the airline industry as a single airline that is an aggregate model of the activities of the entire airline industry. This single airline provides service to all of the markets currently served. Because the ASOM model aggregates the airline industry into a single airline, it exhibits the following limitations:

1. The model reflects airline behavior from an operational rather than a strategic viewpoint and therefore does not consider remaining in markets that prove unprofitable in order to maintain market share.

2. The ASOM model does not model actions taken for reasons of competition. For example, the single airline would choose to use a larger aircraft in shuttle markets rather than have (as is currently the case) eight departures from LGA to DCA in a single hour.

3. The ASOM model balances arrivals and departures each period and does not consider how banking might allow more connections to take place.

4. Aggregate airline responses to economic or policy changes will vary depending on the airport 
characteristics. The differences can be explained by the different markets these airports serve, the different airlines which operate these airports and the different levels of competition which exist at these airports.

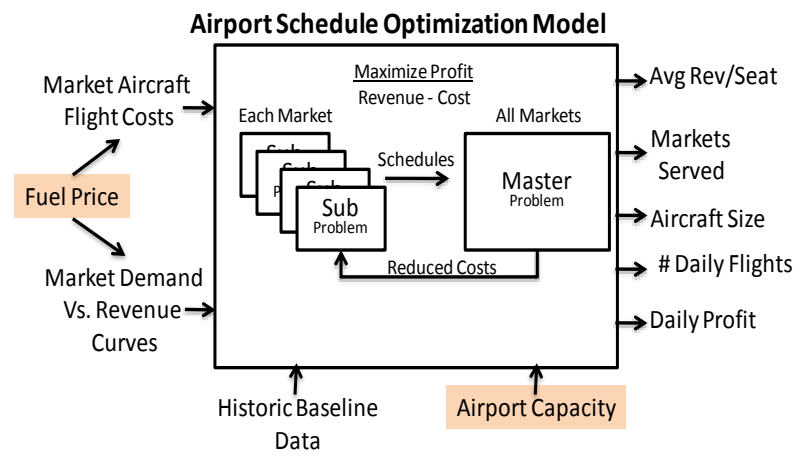

Figure 1. The Airport Schedule Optimization Model (ASOM).

The ASOM model is summarized in Figure 1. The model is base lined on the summer 2007 economic scenario. The inputs to the model are as follows:

(1) Airport capacity limits for domestic operations: The number of scheduled international flights and cargo flight are subtracted from the target airport capacity to obtain the airport capacity for domestic operations. These capacity limits are adjusted to represent visual flight rules (VFR), marginal VFR (MVFR), and instrument flight rules (IFR) conditions.

(2) Airline hedged fuel prices: The baseline price of \$2 per gallon price observed in 3QTR 2007 was used. This price was varied upward in $\$ 1$ increments to $\$ 5$ in order to see how large shocks to operational prices would impact schedules and airfares.

\section{(3) Market operational flight costs by} aircraft type: The total operational cost of a flight is altered based on the aircraft type used. The ASOM allows all aircraft to be considered for specific markets, whether it was used historically or not. Thus, since both fuel costs and crew costs vary by aircraft type, we apply these costs directly to the overall costs using our linear operating cost model that includes as components: fuel costs, maintenance costs, crew costs and other operating costs such as baggage, ticketing and handling.
(4) Market demand versus airfare: Demand curves are derived by taking the summer 2007 data that reflects the percentage of tickets bought at each of the airfare classes for each market served. These curves are adjusted to reflect airfare changes as fuel prices changed - in terms of both changes in slope and intercept - during the period $1^{\text {st }}$ quarter 2005 to $2^{\text {nd }}$ quarter 2010 for each market. The exponential function was found to fit the data (based on regression results) and the demand coefficient was found to decay $3.6 \%(\operatorname{adj} \mathrm{R} 2=90.4 \%)$ for each $\$ 1$ increase in hedged fuel prices. The price coefficient was found to decay $20.1 \%$ (adj R2 = $43.4 \%$ ) for each $\$ 1$ increase in hedged fuel prices, dependent on the market distance. The general form of the Demand curve is provided as Equation 1. Interestingly, our data indicated that long distance market price coefficients were not significantly affected by fuel price changes. However, short haul commuter markets were significantly affected by fuel price changes. These decay rates were applied to the individual market demand versus revenue curves to capture the effects of fuel prices changes.

$$
\text { Demand }=(\text { Demand_Coeff }) * e^{\text {price_coeff*airfare }}
$$

\section{Equation 1. Exponential Demand versus Airfare}

The outputs of the ASOM are a profitable, feasible schedule to each profitable market scheduled by Aircraft Size, Frequency of service and Time of Day. The following metrics can be determined from this schedule:

(1) Number of markets served

(2) Number of daily flights to each markets

(3) Aircraft size chosen for each flight

(4) Average revenue per seat.

(5) Daily profits for each market served

An equilibrium model is used to determine the most profitable schedule. First a collection of feasible schedules was generated for each market and based on these schedules a "master problem" is solved that chooses among these schedules an overall schedule for the airport. This master problem provides a measure of the value of an additional flight within any time period (shadow price information). This shadow price information is used to calculate new schedules for each market. Thus, for each market, new schedules were 
collected based on these shadow prices. All such schedules are added to the master problem.

The master-problem again determines an optimal airport schedule by selecting market schedules that maximizes profit for the airport within the operational capacity of the airport. The process iterates between the solution of the master problem and the generation of new market schedules until no such new schedules improves the master problem. This overall approach is called "Column Generation."

This process continues until either there is no improvement in the total profit (objective function) or no new schedules are generated. Once the problem is solved to linear optimality, if the solution obtained is not integer, a tree search is invoked to prove integer optimality using the same column-generation approach on each branch of the tree.

Previous analysis and papers describe the ASOM in greater detail. [11][12]

\section{B. Data Sources}

The BTS [13] and ASPM [14] data was preprocessed for LGA, EWR, JFK, SFO and PHL airports for third quarter 2007 to calculate the inputs for the ASOM. The following databases were specifically used to preprocess the ASOM data; the ASPM Individual Daily Flight, the T100 monthly flight summaries, the DB1B quarterly passenger itineraries, the P52 quarterly airline costs and the CATSR airport and aircraft data databases.

\section{Design of Experiment}

The results of the ASOM experiment, summarized in the factorial design in Table 2, examined how the airline schedule behavior changed for each of the factors in the design by recording (a) aircraft size, (b) flights per day, (c) markets served, (d) average revenue per passenger seat, and (e) airline profitability.

By evaluating these changes at multiple airports (EWR, JFK, LGA, SFO and PHL), and using the information about the change in the slope and/or intercept of the demand curves when changes in airfares occur, the model can be used to predict how airlines and passengers might react to economic changes that we have not yet witnessed.
The design of the experiment, summarized in table 2 , included 60 possible treatments (5 airports (LGA, EWR, JFK, SFO, PHL) x 3 capacity levels x 4 hedged fuel prices $\mathrm{x} 1$ set of passenger demand versus price curves summer 2007 economic conditions).

\begin{tabular}{|c|c|c|c|c|c|c|c|}
\hline \multicolumn{3}{|l|}{ Inputs } & \multicolumn{5}{|l|}{ Outputs } \\
\hline Airports & $\begin{array}{l}\text { Fuel } \\
\text { Price }\end{array}$ & $\begin{array}{l}\text { Airport } \\
\text { Capacity }\end{array}$ & \begin{tabular}{|l|} 
Markets \\
Served
\end{tabular} & \begin{tabular}{|l|} 
\# Flights \\
per day
\end{tabular} & $\begin{array}{l}\text { Average \$ } \\
\text { per Seat }\end{array}$ & $\begin{array}{l}\text { Average } \\
\text { seats size }\end{array}$ & $\begin{array}{l}\text { Daily Airline } \\
\text { Profit }\end{array}$ \\
\hline LGA & $\$ 2$ & IFR & \multirow{4}{*}{\multicolumn{5}{|c|}{$\begin{array}{c}5 \text { airports X } 4 \text { Fuel Prices X } 3 \\
\text { Capacity Limits }=60\end{array}$}} \\
\hline EWR & $\$ 3$ & MVFR & & & & & \\
\hline JFK & $\$ 4$ & VFR & & & & & \\
\hline SFO & $\$ 5$ & & & & & & \\
\hline PHL & & & & & & & \\
\hline
\end{tabular}

Table 2. The ASOM design of experiment.

Note: These experiments include analysis of hedged fuel prices of \$5/gallon. Historically, fuel prices have not exceeded \$3.70/gallon (07/2008). These results are reported, but it should be recognized that above $\$ 4 /$ gallon the economy, these are wholesale prices paid by the airline and passenger demand may undergo significant changes that have not be reflected in our current model.

\section{Statistical Analysis}

The following outputs of the ASOM were analyzed: (1) the number of profitable markets served, (2) the daily domestic flights by market, (3) the average revenue per seat, (4) the average aircraft size in seats per operation, and (5) the overall profitability of each airport studied. The controls or exogenous factors for the model are fuel prices and airport capacity limits.

The analysis of statistically significant trends between the exogenous factors and the ASOM outputs required the following multi-step process:

(1) The ASOM output data was processed into the metrics of interest at the airport level.

(2) A step-wise regression was performed to identify the factors that most impact the independent variable. Stepwise regression adds variables sequentially, choosing the most significant variable first and continues until the adding of another variable degrades the relative $\mathrm{R} 2$ coefficient (i.e. the $\mathrm{R} 2$ adjusted for the number of independent terms in the regression equation). 


\section{RESULTS OF ANALYSIS}

\section{A. Effects of increase of $\$ 0.45$ in Fuel Prices on Airline Behavior}

Table 3 shows the effects of increasing hedged fuel prices by $\$ .45$ per gallon (e.g. equivalent to doubling landing fees from $\$ 1000$ to $\$ 2000$ per operation). On average for all five airports the ASOM aggregated airline reduces markets by $0.9 \%$, decreases scheduled flights per day to all markets by $1.0 \%$, increases average airfare by $4.5 \%$, decreases average aircraft size by $1.3 \%$, and increases daily airline profits by $0.3 \%$.

\begin{tabular}{|c|c|c|c|c|c|c|}
\hline \multirow{2}{*}{$\begin{array}{c}\text { For MVFR } \\
\text { airport } \\
\text { capacity }\end{array}$} & \multicolumn{6}{|c|}{$\%$ change for \$.45 increase in Fuel Prices } \\
\cline { 2 - 7 } & PHL & LGA & JFK & EWR & SFO & All 5 \\
\hline Markets & $-1.1 \%$ & $0.0 \%$ & $0.0 \%$ & $-0.9 \%$ & $-2.6 \%$ & $-0.9 \%$ \\
\hline Daily Flights & $-0.8 \%$ & $-0.8 \%$ & $-0.7 \%$ & $-0.7 \%$ & $-2.6 \%$ & $-1.0 \%$ \\
\hline Rev/ Seat & $+3.6 \%$ & $+5.8 \%$ & $+7.4 \%$ & $+5.6 \%$ & $+2.4 \%$ & $+4.5 \%$ \\
\hline Gauge & $-0.1 \%$ & $-2.6 \%$ & $-1.1 \%$ & $-1.4 \%$ & $-1.3 \%$ & $-1.3 \%$ \\
\hline Daily Profits & $+2.4 \%$ & $-1.3 \%$ & $+3.2 \%$ & $+2.2 \%$ & $-3.0 \%$ & $+0.3 \%$ \\
\hline
\end{tabular}

Table 3. Effects of increase of $\$ \mathbf{\$ 0 . 4 5}$ in Fuel Prices on Airline Behavior.

Tables 3 and 4 illustrate the differences in modeled aggregate airline behavior between the five airports examined. The differences can be explained by the different markets these airports serve, the different airlines which operate these airports and the different levels of competition which exist at these airports.

The observed differences in response to fuel price increases were that LGA and JFK did not reduce markets. JFK's revenue per seat (or airfares) increased $\sim 50-300 \%$ more than the other airports. PHL showed negligible changes in aircraft size or gauge. PHL, JFK, and EWR increased airline profits where the others lost profits.

\section{B. Effects of reduction of 4 operations per hour on Airline Behavior}

Table 4 shows the effects on airline behavior in response to a $\$ .45$ per gallon increase in hedged fuel prices (e.g. equivalent to doubling landing fees from $\$ 1000$ to $\$ 2000$ per operation). On average for all five airports the ASOM aggregated airline reduces markets by $0.9 \%$, decreases scheduled flights per day to all markets by $1.0 \%$, increases average airfare by $4.5 \%$, decreases average aircraft size by $1.3 \%$, and increases daily airline profits by $0.3 \%$.

\begin{tabular}{|c|c|c|c|c|c|c|}
\hline \multirow{2}{*}{$\begin{array}{c}\text { For 3QTR 07 } \\
\text { Fuel Prices }\end{array}$} & \multicolumn{5}{|c|}{$\begin{array}{c}\text { \% change for capacity reduction of } 4 \\
\text { operations per hour }\end{array}$} \\
\cline { 2 - 7 } & PHL & LGA & JFK & EWR & SFO & All 5 \\
\hline Markets & $-1.2 \%$ & $-0.4 \%$ & $-0.9 \%$ & $-0.2 \%$ & $0.0 \%$ & $-0.6 \%$ \\
\hline Daily Flights & $-2.8 \%$ & $-2.4 \%$ & $-0.6 \%$ & $-1.8 \%$ & $-0.2 \%$ & $-1.5 \%$ \\
\hline Rev/ Seat & $0.0 \%$ & $0.3 \%$ & $0.1 \%$ & $0.5 \%$ & $0.1 \%$ & $0.2 \%$ \\
\hline Gauge & $0.6 \%$ & $0.3 \%$ & $0.3 \%$ & $0.3 \%$ & $0.0 \%$ & $0.3 \%$ \\
\hline Daily Profits & $-1.6 \%$ & $-1.5 \%$ & $-0.1 \%$ & $-0.7 \%$ & $0.0 \%$ & $-0.7 \%$ \\
\hline
\end{tabular}

Table 4. Effects of reduction of 4 operations per hour on Airline Behavior.

The observed differences in response to increases in hedged fuel prices were that EWR and SFO did not reduce markets significantly. SFO did not reduce daily flights significantly. LGA and EWR slightly increased revenue per seat (or airfares). SFO showed negligible changes in aircraft size or gauge. SFO and JFK showed negligible changes in airline profits.

\section{Geographic Access}

The ASOM considers the competition among markets for airline resources and chooses schedules that optimize the aggregated airline's profitability using prices that were set historically in a competitive environment. Thus, if a market loses service, it is either because, under current economic conditions, it is no longer profitable to serve the market or because when restrictions on runway access are imposed, it is more profitable to use that access in other markets.

Profitable Markets. The results from a statistical examination of the changes in the number of markets served shows a significant relationship ( $95 \%$ confidence) between markets served with direct service and two factors: average revenue per seat and capacity limits on runway access. As capacity limits decrease, the number of markets served also decreases. The reverse relationship exists for average revenue per seat, i.e. whenever revenue per seat increases the number of markets served decreases. The correlation accounted for $45.1 \%$ (i.e. $\mathrm{R}$-squared) of the observed variation in 
profitable markets served. The regression equation is shown below:

Profitable direct Markets $=64.9+(0.23 *$ Caps $)$ $-(.178 *$ average revenue per seat)

\section{Equation 2. ASOM Profitable Market}

Scheduled Flights per Day. The results from a statistical examination of the changes in the number of scheduled daily flights shows a significant relationship ( $95 \%$ confidence) between number of scheduled daily flights and two factors: number of markets served and capacity limits on runway access. As capacity limits decrease, the number of scheduled daily flights decreases. Similarly, as the number of markets served increases, the number of scheduled daily flights increases. The correlation accounted for $70.8 \%$ (i.e. $\mathrm{R}$-squared) of the observed variation in scheduled daily flights. The regression equation is shown below:

Scheduled Flights per day $=28.3+$ $(2.62 *$ Caps $)+(7.68 *$ \# Markets Served $)$

\section{Equation 3. ASOM Scheduled Daily Flights}

\section{Economic Accessibility}

Average revenue per seat is examined to determine how airline airfares increase, as capacity limits are imposed, or as economic conditions change.

Average Revenue per Seat. The results from a statistical examination of the changes in the average revenue per seat show a significant relationship (95\% confidence) between average revenue per seat and one factor: hedged fuel prices. As hedged fuel prices increase, the average revenue per seat also increases. This correlation accounted for $11.3 \%$ (i.e. R-squared) of the observed variation in average revenue per seat. The regression equation is shown below:

Average Revenue per Seat $=\$ 86.61+$ (16.7*Hedged Fuel Price)

Equation 4. ASOM Average Revenue per Seat

\section{E. Airline Profitability}

The ASOM generates optimally profitable airline schedules and calculates the total revenue and costs from this schedule. Taking operating revenues minus operating costs provides the aggregate industry operating profit per quarter for the airports modeled. Airline profitability for the routes serviced is a complex phenomenon driven by demand for air transportation, passenger's responses to price increases, and operating costs.

Daily Airline Airport Profit. The results from a statistical examination of the changes in the daily airline profits show a significant relationship (95\% confidence) between daily airline profits and three factors: average revenue per seat, average aircraft size, and flights per day. As average revenue per seat, average aircraft size, and flights per day increase, the daily airline profits also increases. This correlation accounted for $92.0 \%$ (i.e. R-squared) of the observed variation in daily airline profits. The regression equation is shown below:

Daily Airline Profit $(\$ M)=-\$ 22.256+$ $\left(0.0536^{*}\right.$ average revenue per seat $)+\left(0.1007^{*}\right.$ average aircraft size $)+(0.01388 *$ flights per day $)$

Equation 5. ASOM Daily Airline Airport Profit

\section{F. Air Transportation Efficiency}

Air transportation efficiency is measured by the throughput of passengers through the airspace network. This study is only examining whether there is upgauging of aircraft and therefore more passengers being able to depart and arrive at EWR. Thus, this section will evaluate whether airlines tend to up gauge or down-gauge as the result of changes in runway capacity and changes in operating costs.

Average Aircraft Size. The results from a statistical examination of the average aircraft size show a significant relationship (95\% confidence) between daily average aircraft size and three factors: average revenue per seat, markets served, and flights per day. As average revenue per seat, and flights per day increase, the average aircraft size decreases. Average aircraft size was found positively correlated with the number of markets and negatively correlated with the average revenue per seat and flights per day. This correlation accounted for $85.7 \%$ (i.e. R-squared) of the observed variation in daily average aircraft size. The regression equation is shown below: 
Average Aircraft Gauge $=250.4-(0.372 *$ average revenue per seat $)-(.262 *$ flights per day $)+$ (1.38* markets served)

\section{Equation 6. ASOM Average Aircraft Guage}

These results from the ASOM model were not surprising because of the lack of economies of scale related to up gauging. A closer examination of the data shows that 100 and 200 seat classes show poor historic performance (cost per seat-hr). The newest part of the airline industry fleet is regional jets that are more fuel efficient that the larger aircraft in the overall fleet. Thus, as fuel prices increase, there is more incentive for airlines $t$ (based on the current fleet configuration) o move to smaller aircraft, since the smaller aircraft have better average cost per seat hour. The B787 and A380 are more efficient aircraft but unlikely to be used for many of the markets currently served by these airports since they are relatively large aircraft.

By using smaller aircraft the airlines can assure high load factors and greater frequency. This result has significant implications for future airspace use.

\section{CONCLUSIONS and FUTURE WORK}

\section{Conclusions}

This research indicates that airport capacity limits (within the range studied) do not have significant negative effects on either markets served or on airfares charged. As capacity limits are imposed (i.e. -4 operations per hour), the ASOM aggregated airline reduces markets by $0.6 \%$, decreases scheduled flights per day to all markets by $1.5 \%$, increases average revenue per seat by $0.2 \%$, increases average aircraft size by $0.3 \%$, and reduces daily airline profits by $0.7 \%$.

Hedged fuel prices and economic health drive air transportation performance: Regulatory authority to manipulate the market through the introduction of airport capacity (and airport capacity limits) is only one of three factors affecting geographic access, market access, and airline financial stability. Passenger demand for air transportation (measured by national unemployment rate) and airline operating costs (determined by fuel prices) have significant impacts. As hedged fuel prices increase $\$ .45$ per gallon (e.g. equivalent to doubling landing fees from $\$ 1000$ to $\$ 2000$ per operation), the ASOM aggregated airline reduces markets by $0.9 \%$, decreases scheduled flights per day to all markets by $1.0 \%$, increases average airfare by $4.5 \%$, decreases average aircraft size by $1.3 \%$, and increases daily airline profits by $0.3 \%$.

Aggregate airline responses to economic or policy changes will vary depending on the airport characteristics. The differences can be explained by the different markets these airports serve, the different airlines which operate these airports and the different levels of competition which exist at these airports.

Combination of increased passenger demand and increased operating costs directly causes increase in aircraft size. It is financially viable for airlines to up gauge to service the passenger demand.

In the presence of increased passenger demand and in the absence of significant airline competition the airline industry will increase aircraft size. However, the ability to up-gauge in the real-world is restricted by additional factors not modeled: (1) the capital costs of purchasing new aircraft since there is a lack of available aircraft at the 90-120 seat size (2) the airline's preference toward frequency (in order to maintain market share and provide passengers with more time-specific options), and (3) labor cost structures for pilots that are significantly higher for larger aircraft than for regional jets.

\section{Future Analysis}

Further ASOM analysis will examine additional congested airports to see if the differences in airline behavior can be categorized by airport type. Additional analysis will be conducted to determine the effect of aircraft costs and burn rates on airline behavior and how this effects economic access, geographic access, airline profitability and air transportation efficiency.

\section{Acknowledgements}

We gratefully acknowledge the support and assistance from Mike Madson, John Cavalowsky, and Michael Bloem of NASA. We would also like 
to acknowledge the contributions of Jim Gaughn, Norm Fujisaki, Terry Thompson, and Jack Kres of Metron Aviation and Frank Berardino (GRA), Robert Poole (Reason Foundation), and Matt Blake (Sensis). We also are grateful for the database support Guillermo Calderon-Meza provided throughout this research effort. This research was sponsored by NASA NRA NNX07AT23A.

\section{REFERENCES}

[1] P. Belobaba, A. Odoni, and C. Barnhart, The global airline industry. Wiley, 2009.

[2] FAA, FAA Aerospace Forecast: Fiscal Years 2011-2031. U.S. Department of

Transportation Federal Aviation Administration Aviation Policy and Plans, 2011.

[3] G. L. Donohue and D. Shaver III, Terminal Chaos: Why US Air travel is broken and how to fix it. American Institute of Aeronautics and Astronautics, 2008.

[4] Federal Aviation Administration, "FACT 2 Report, Capacity Needs in the National Airspace System, 2007-2025," The MITRE Corporation, McLean, Virginia, 2007.

[5] NEXTOR et al., "Total Delay Impact Study A Comprehensive Assessment of the Costs and Impacts of Flight Delay in the United States," NEXTOR, Oct-2010.

[6] C. E. Schumer, Flight Delays Cost Passengers, Airlines and the U.S. Economy Billions. Joint Committee Majority Staff, 2008.

[7] FAA, FAA Airport Improvement Program and American Recovery and REinvestment Act Projects - Fiscal Years 2005-2009. 2010.

[8] FAA, FAA's NextGen Implementation Plan. 2011.

[9] M. Ball, G. Donohue, and K. Hoffman, "Auctions for the safe, efficient, and equitable allocation of airspace system resources," Combinatorial auctions, vol. 1, 2006.

[10] L. T. Le, "Demand Management At Congested Airports: How Far Are We From Utopia?," George Mason University, 2006.

[11] G. Donohue, K. Hoffman, L. Sherry, J. Ferguson, and A. Q. Kara, Optimizing Air Transportation Service to Metroplex Airports Part 1: Analysis of Historical Data. 2010.
[12] G. Donohue, K. Hoffman, L. Sherry, J. Ferguson, and A. Q. Kara, Optimizing Air Transportation Service to Metroplex Airports Part II: Analysis Using the Airline Schedule Optimization Model (ASOM). 2010.

[13] U.S. DOT/BTS, "U.S. Department of Transportation, Bureau of Transportation Statistics. "National Transportation Statistics."," BTS TranStats, 2010. [Online]. Available: http://www.transtats.bts.gov/.

[14] FAA, "The Federal Aviation Administration. "Aviation system performance metrics (ASPM)-complete"," 2010.

\section{Integrated Communications Navigation and Surveillance (ICNS) Conference}

May 10-12, 2011 